\section{Trying an authorship index}

SIR - Few issues in scientific life can now match authorship of collaborative work for its potential to distract and destroy. The use of bibliometric indices as performance indicators places great weight upon uncertain foundations. How does one compare senior versus junior, staff member versus visitor, money versus time, or backache versus headache versus heartache?

The unit in which I work uses a set of formal rules based upon a simple points table. The maximum score possible is 100 points. Each potential author is awarded the highest realistic score in each category; whoever achieves a total of 25 points is offered joint authorship in rank order of total score. In the event of ties, recent near-misses are considered; if none exists, alphabetical order is used.

The scheme is used mainly for ex-

\section{No friction}

SIR - The news item "Friction continues over costs" (Nature 351, 594; 1991) greatly overstates the difficulties in the interaction between the European particle physics centre in Geneva (CERN) and the Superconducting Super Collider Laboratory in Texas (SSCL). In fact, the Memorandum of Understanding that we signed in April is working well. Scientists from our laboratories are working together effectively on matters of accelerator design, technology development, and other issues of mutual interest and concern; and we expect the cooperation to continue.

Both of us have always recognized and acknowledged the complementary nature of the programmes of CERN and the SSCL. CERN is one of the world's major centres for high-energy physics; the SCCL is becoming one. Outstanding scientists from around the world work at the two laboratories, and their cooperation can only enhance the quality of scientific work in this exciting and rapidly developing field.

The frontiers of physics are always characterized by some degree of competition among scientists striving to make critical discoveries, but this competition fosters and improves scientific programmes and should not be confused with disruptive "friction".

CARLO RUBBIA Director-General

CERN, CH-1211, Geneva 23, Switzerland

ROY SCHWITTERS Director

$S S C L$

2550 Beckleymeade Avenue,

Dallas, Texas 75237, USA for themselves?

NERC Unit of Comparative Plant

Ecology,

Department of Animal and

Plant Sciences,

The University,

Sheffield S10 2TN, UK

\section{COAUTHORSHIP SCORING SYSTEM}

\section{INTELLECTUAL INPUT}

(planning/designing/interpreting)

perimental papers in plant ecology. A variant for theoretical studies has a 15point scale for data-capture and a 25point scale for specialist input. However, we have avoided too much tinkering because simplicity and generality are important goals. Preliminary experience with these rules has been encouraging perhaps readers may wish to test them

RODERICK HUNT No contribution

One detailed discussion

Several detailed discussions

Correspondence or longer meetings

Substantial liaisons

Closest possible involvement

PRACTICAL INPUT: DATA-CAPTURE (setting-up/observing/recording/abstracting) No contribution

Small contribution

Moderate indirect contribution

Moderate direct contribution

Major indirect contribution

Major direct contribution

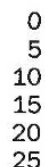

PRACTICAL INPUT: BEYOND DATA-CAPTURE (Data processing/organizing)

No contribution

Minor or brief assitance

Substantial or prolonged assistance

SPECIALIST INPUT FROM RELATED FIELDS

No contribution

Brief or routine advice

Specially-tailored assistance

Whole basis of approach

\section{LITERARY INPUT}

(contribution to first complete draft of manuscript

No contribution

Edited others' material

Contributed small sections

Contributed moderate proportion

Contributed majority

Contributed virtually all

\section{Proof negative}

SIR - In his Commentary 'Does climate still matter?' (Nature 350, 649-652; 1991), Jesse H. Ausubel argues that "we seem to be 'climate-proofing' society, making ourselves less subject to natural phenomena". He notes that this is heartening and that it "would seem sensible to maintain this course and not to revert to reliance on ... technologies ... that are more sensitive to climate".

Curiously, he fails entirely to recognize that climate-proofing has depended heavily on the increased use of fossil fuels. In order to limit emissions, it is widely argued that we must ultimately reduce global use of fossil fuels and increase our dependence on energy sources such as biomass fuels, wind, hydropower and solar energy. Yet doing so may increase our vulnerability to climate change.

Ausubel himself notes that "a system of energy from wood and hay was more climatically sensitive than one reliant on oil and natural gas". He adds that water and wind power "are, of course, more sensitive to climate".

The threat of climate change confronts us with not one challenge but two. We must not only reduce emissions but also our vulnerability to changing climates. As in Ausubel's analysis, these are often treated as separate problems. Consequently, an important dilemma has been largely overlooked: the shift away from fossil fuels may increase our vulnerability to climate change at precisely that moment in history when we need to "climate-proof" ourselves.

NICK SUNDT

1347 Massachusetts Avenue SE, Washington, DC 20003, USA

\section{Sampling error?}

SIR - Others have drawn attention to serious anomalies in the procedure undertaken for radiocarbon dating the Shroud of Turin (Damon et al. Nature 337, 611-615; 1989).

Your readers should know that anxiety about the procedures followed has been heightened by a recent declaration of Professor Wolfli, one of the 21 co-authors of Damon's report. In a short interview published in the French monthly journal Contre-Reforme Catholique, Wolfli asserts that the size and weight of the shroud samples mentioned in Damon's paper were erroneous. According to the French journal, he declared: "Nobody (among the authors) has seen this error. We were under pressure, but that is not an excuse." So far, this statement has not been challenged in any way by the first author, Damon. Because sampling procedures have always been regarded as critical in the dating of the shroud, this situation is most disturbing.

This unique archaeological artefact deserves more serious attention. Logically, scientists who question this procedure should be allowed to review the original records, including the videotapes recorded during sample collection in Turin in April 1988. How can this be achieved?

PIERRE BUSSON

Lineberger Cancer Research Center,

University of North Carolina,

Campus Box 7295, Chapel Hill,

North Carolina 27516, USA 